\title{
Financial and environmental consequences of a voluntary farm environmental assurance program in Michigan
}

\author{
C. Vollmer-Sanders, C. Wolf, and S.S. Batie
}

\begin{abstract}
The Michigan Agriculture Environmental Assurance Program is a voluntary environmental management program for Michigan farms. The Michigan Agriculture Environmental Assurance Program encourages farm managers to become better environmental stewards through writing Comprehensive Nutrient Management Plans and incorporating changes to comply with regulations as well as generally accepted management practices and recommendations. Early-adopting livestock producers with verified operations were interviewed to identify and measure costs incurred, environmental outcomes achieved, and producer attitudes and perceptions as a result of verification. The average total cost to become verified was $\$ 120,600$ per farm, of which the average producer paid $\$ 104,423$, with the remaining $\$ 16,177$ provided through cost-share funds. Much of this cost was for long-term investments such as manure storage and facilities improvements. Producers realized an average postverification annual cost savings of $\$ 2,792$ by curtailing unnecessary use of commercial fertilizer.The financial values had large amounts of variation in every case. The per animal unit costs of verification were generally in the same range as the US Environmental Protection Agency estimates for cost of compliance with similar (but mandatory) proposed regulations. With respect to environmental outcome, after verification, average operation mass balance improved. The primary motivation to participate in the program stemmed from existing or potential environmental regulations.
\end{abstract}

Key words: agriculture — agroenvironmental programs-Michigan—voluntary

\begin{abstract}
As it becomes clear that agriculture is a source of potential pollution that will eventually be subjected to increased regulation of some form, voluntary approaches to environmental protection and management have received increased attention as a foreshadowing of the costs of regulatory compliance (Alberini and Segerson 2002; Poe et al. 2001). Most economic analyses focus on policy design and incentives to control environmental externalities of agricultural production. This paper examines the results and experiences of the early adopters of a voluntary program by Michigan livestock farms. The objective is to understand farm-level motivation of early adopters and consequences of participation, including costs and environmental impacts, and draw relevant lessons for policymakers and farmers.
\end{abstract}

tion underlying the MAEAP is that those livestock producers who follow the environmental management strategies laid out in the CNMP and who follow the MAEAP educational program recommendations will reduce the risk of pollution discharges, nuisance complaints, and lawsuits.

To examine the economic and environmental effectiveness of the MAEAP, we interviewed 29 operators managing 31 MAEAP-verified, or nearly verified, livestock operations, as of January 1, 2005. The interviews collected farm characteristics as well as the operators' perception of the financial implications of complying with the MAEAP and environmental changes related to compliance. In addition, the costs associated with MAEAP verification and environmental impacts as measured by phosphorus (P) management were estimated using data from both interviews and secondary sources. Farm-specific CNMPs were also analyzed to determine the environmental changes that resulted from MAEAP verification.

This article presents the results of a set of detailed, in-person interviews with early adopters of a voluntary environmental compliance program. The primary objective of this analysis was to understand those financial and environmental outcomes of this voluntary program, which can be used to estimate the costs and consequences of environmental regulatory programs on livestock agriculture. The results may be of use to policymakers, industry personnel, and academics interested in policy implementation, as well as farm managers considering voluntary environmental compliance programs.

Michigan Agriculture Environn Assurance Program (MAEAP) is a voluntary program created in 1998 by multiple Michigan governmental, industry, and university entities to assist agricultural producers with nutrient management (MAEAP 2011) The MAEAP certification requires that the farm has an accurate and complete Comprehensive Nutrient Management Plan (CNMP) and that the producer has or will implement the environmental management practices in that CNMP on a schedule approved by the Michigan Department of Agriculture. The development of a CNMP involves a close examination of farm nutrient balance and flows. For example, the CNMP accounts for the nutrient content of manure and commercial fertilization applications as well as requiring the maintenance of accurate manure application records. The assump-

\section{Materials and Methods}

The potential interview pool included all fied by January 1, 2005. A total of 46 eligible (i.e., verified) producers received an information packet through the mail that included an outline of participant expectations and a letter of support from the Michigan

Carrie Vollmer-Sanders is the Western Lake Erie Basin Project Director of The Nature Conservancy in Kalamazoo, Michigan. Christopher Wolf is a professor in the Department of Agricultural, Food and Resource Economics, Michigan State University, East Lansing, Michigan. Sandra S. Batie is the Elton R. Smith Professor in the Department of Agricultural, Food and Resource Economics, Michigan State University, East Lansing, Michigan. livestock producers that were MAEAP veri- 
Department of Agriculture. For willing participants, informal personal interviews were conducted at their operations in January and February of 2005.

The 29 livestock operators interviewed in this research represented $63 \%$ of all MAEAP-verified livestock operators at that time (early adopters). The operators interviewed managed a total of 31 operations of all major livestock species (beef and dairy cattle, hogs, and poultry) across a wide range of farm sizes. The interview questionnaire included both closed and open-ended questions that encompassed farm status, nutrient management planning and operation, farm characteristics and changes, managerial and capital changes, opinions, environmental impacts, and operator characteristics. Each interview was designed to allow the livestock producers to expand on issues if desired.

For the purposes of this research, each livestock producer was labeled by primary enterprise. If a livestock producer raised more than one species, the largest livestock enterprise was specified as the "primary enterprise." For example, several operations had dairy cows and beef cattle, but if the dairy cattle outnumbered the beef cattle, then dairy was considered the primary enterprise, and these operators were considered dairy producers.

Costs. The costs associated with becoming MAEAP-verified were categorized in several ways. First, costs were either related to writing the CNMP (for example, plan-writer fees, tests of soil and manure, or managerial labor and time) or were the result of changes made to implement the plan. The changes could further be subdivided into the cost of capital investments (for example, buildings, gutters, manure storage, or machinery and equipment) and operating expenses (such as record keeping or additional manure hauling costs).Additionally, cost share funds were provided to some farms, such as those obtained from the Environmental Quality Incentives Program (EQIP) administered by the USDA Natural Resources Conservation Service to offset eligible investments in capital improvements and for the writing of the CNMP.Any cost share funds were accounted for in calculating net farm cost.

In order to accurately compare costs across time, all costs were adjusted to 2004 dollars using the Producer Price Index (US Bureau of Labor Statistics 2005). The total cost of writing, implementing, and maintaining MAEAP verification included the CNMP price, cost of any change in managerial practices, and cost of any change in or additional capital investments. The annual cost of implementing and maintaining MAEAP verification included managerial costs, which were composed of annualized technical service provider or crop consultant fees, and annualized capital investment. Supervision and record-keeping labor was calculated based on a labor fee of $\$ 16 \mathrm{~h}^{-1}$. Change in soil and manure testing cost was calculated using the number of additional tests at an average cost of $\$ 7$ per soil sample and $\$ 32$ per manure sample.

Equipment and machine use, manure spreading labor, and fuel associated with MAEAP verification were calculated using a computer spreadsheet developed at the University of Missouri (Massey 1998). The size and type of equipment was altered to match each operation. A charge of $\$ 0.61$ $\mathrm{L}^{-1}\left(\$ 2.30 \mathrm{gal}^{-1}\right)$ was used for fuel cost. The hourly wage for manure spreading labor was calculated at $\$ 10 \mathrm{~h}^{-1}$ plus an additional $\$ 2 \mathrm{~h}^{-1}$ to account for benefits, bonuses, and other compensation (USDA NASS 2004). The P and nitrogen savings or cost was based on the Crops and Livestock Budget Estimates for Michigan (Dartt and Schwab 2001). These costs were then multiplied by the US Bureau of Labor Statistics Producer Price Index to convert all monetary values to 2004 dollars.

Because the expenses included operating expenses as well as long-term capital investments, all expenses were annualized to facilitate comparisons across operations. Machinery and equipment costs were annualized using 7-year straight-line depreciation, while longer-term capital investments, such as buildings, were annualized using 20-year straight-line depreciation. Operational costs were summed to annual values. Permanent operational cost changes were totaled by summing the costs in real terms through 2008. The initial CNMP writing fee was incurred only once, but any cost to update the CNMP was considered an annual operational cost. All costs were inflated to 2004 dollars (the time of data collection) to make expenses comparable over time.

The costs were examined by species and farm size. Averages, standard deviations, minimums, and maximums are reported for dairy, beef, swine, and poultry farms when there were five or more observations. (For confidentiality concerns, only averages are reported when less than five farms were in that group). Also, farm size was reflected by separating the operations into animal feeding operations (AFOs) and confined animal feeding operations (CAFOs), where CAFOs had at least 1,000 animal units (AU).

A CAFO is defined as equal to or more than 1,000 AUs. An AFO is defined as less than 1,000 AUs. An AU is a metric of manure generation used to assess the size of operations across animal species. One AU was defined as 1 feeder calf, heifer, or steer; 0.7 mature dairy cows (whether a milking or dry cow); 25 pigs weighing over $25 \mathrm{~kg}$ (55 lb); 0.5 horses; 10 sheep or lambs; 55 turkeys; 100 laying hens or broilers when the facility has an unlimited continuous flow watering systems; or 30 laying hens or broilers when the facility has a liquid manure handling system (MDA 2008).

Environmental Risks: Phosphorus. Environmental data were analyzed with the assistance of the Michigan State University Institute of Water Research and Michigan State University Extension personnel. A cropland $\mathrm{P}$ mass balance and a phosphorus index (P-Index) were calculated to examine the differences between the operation before and after MAEAP verification. (Ideally, an analysis would be based on the net costs or environmental risks with and without MAEAP verification rather than before and after. Because this research necessarily had to rely on before and after data, some costs may be biased upwards, sometimes significantly where capital investments in machinery and manure storage are involved. Where such bias can be expected, it is indicated in the article.) The cropland $\mathrm{P}$ mass balance accounted for all input and output $\mathrm{P}$ in one year and was calculated using information from the CNMP.The CNMP specified values for most variables necessary to calculate the mass balance. The computed value was considered the "after" MAEAP verification P mass balance. To determine environmental change due to MAEAP verification, a "before" and "after" $P$ mass balance was calculated from interview and plan information. These questions addressed changes in manure sold, feed rations, cropland, number of AUs, and crop rotations.

To determine farm environmental risk, the operations were evaluated based on cropland P mass balance and whether they were within $0.40 \mathrm{~km}(0.25 \mathrm{mi})$ of a stream. If the operation was out of mass balance after becoming MAEAP verified (or a change in their mass balance score indicated that there 
Table 1

Descriptive statistics of the Michigan Agriculture Environmental Assurance Program (MAEAP)-verified producers and operations.

\begin{tabular}{|c|c|c|c|c|c|c|c|}
\hline Description & Beef* & Dairy & Poultry & Swine & All farms & CAFOT & AFO¥ \\
\hline Producers interviewed & 3 & 10 & 4 & 12 & 29 & 15 & 14 \\
\hline Operations represented & 3 & 10 & 5 & 13 & 31 & 17 & 14 \\
\hline Post-MAEAP average & 526 & 2,387 & 1,103 & 708 & 1,295 & 1,871 & 597 \\
\hline Change from Pre-MAEAP & -197 & +474 & +403 & -249 & +89 & +436 & -331 \\
\hline Post-MAEAP minimum & & 690 & 0 & 190 & 0 & 0 & 0 \\
\hline \multicolumn{8}{|l|}{ Animal units } \\
\hline Post-MAEAP average & 417 & 1,994 & 7,808 & 1,146 & 2,424 & 3,999 & 510 \\
\hline Change from Pre-MAEAP & +7 & -597 & 0 & 0 & -192 & -351 & +1 \\
\hline Post-MAEAP minimum & & 309 & 405 & 160 & 47 & 1,100 & 47 \\
\hline Post-MAEAP maximum & & 3,660 & 17,873 & 4,054 & 17,873 & 17,873 & 1,058 \\
\hline \multicolumn{8}{|l|}{ Percent manure sold } \\
\hline Post-MAEAP maximum & & 33 & 100 & 100 & 100 & 100 & 100 \\
\hline
\end{tabular}

* Because only three beef farms were included, minimum and maximum values are not reported.

† CAFO is a concentrated animal feeding operation defined as equal to or more than 1,000 animal units.

$\ddagger \mathrm{AFO}$ is an animal feeding operation defined as less than 1,000 animal units.

was an increased amount of $\mathrm{P}$ on farm, but the operation was not out of mass balance), the operation was placed in the high-risk category. Farms categorized as high risk had a greater chance of $\mathrm{P}$ leaving the farm. Twelve operations were considered high risk. The high-risk fields of the high-risk operations were then evaluated with a P-Index.

Phosphorus indices must be specific to local topography, hydrology, management conditions, and policy decisions (Sharpley et al. 2003). The P-Index used scored each field by applying a number, associated with the level of $\mathrm{P}$ runoff risk, to evaluate the level of $\mathrm{P}$ transport and the source of P.The P transport variables included the Revised Universal Soil Loss Equation Version 2 (RUSLE2) score, proximity to surface water, the number of intermittent streams, soil hydrology, and crop rotation. The RUSLE2 is an equation that estimates soil loss from rill and interrill erosion on a field caused by rainfall on cropland. Potential sources of $\mathrm{P}$ included the influences of the following variables: soil $\mathrm{P}$ as indicated by a soil test, commercial fertilizer applications, manure spreading methods, amount of manure, and an existing cover crop. Each variable received a score of zero, one, two, four, or eight, with a score of zero indicating low risk and eight indicating high risk. Each field could receive a P-Index score ranging from 0 to 68 . A field that had a total score of less than 18 on the P-Index was categorized as having low potential for P loss.

Only the high-risk fields of the high-risk operations were scored with the P-Index. It was assumed that if the fields with the highest risk of polluting surface water were evaluated and scored below the threshold, then the fields with less risk of polluting surface water would also score below the threshold. A high-risk field was selected for evaluation based on (1) proximity (within $91.44 \mathrm{~m} \mathrm{[300}$ $\mathrm{ft}$ ) to surface water, (2) soil level of $\mathrm{P}$ above $150 \mathrm{ppm}\left(300 \mathrm{lb} \mathrm{ac}^{-1}\right)$, or (3) a high Manure Application Risk Index (MARI) score. The MARI identifies areas that may safely receive manure applications. It also defines the seasons and weather conditions when manure application is allowed for that land. A field with a high MARI rating cannot have any manure spread in the winter because application of manure would not be safe for the environment (Ouyang and Laboski 2005). Fields from an operation that met one or more of the three criteria were compiled, and then within this set, eight fields were randomly selected to conduct the P-Index calculation. If an operation did not have eight fields that met at least one criterion, either six fields were selected to conduct the P-Index calculation or the set of tested fields were opened to those fields that had a soil $\mathrm{P}$ level between 75 to $150 \mathrm{ppm}$ (150 to $300 \mathrm{lb}$
$\mathrm{P} \mathrm{ac}^{-1}$ ) and/or a medium MARI score. Some operations may not have a change in the $\mathrm{P}$ mass balance or the P-Index depending on the operation's level of pollution prevention in place prior to MAEAP verification.

\section{Results and Discussion}

Program Participant Characteristics. Summary characteristics of the operations interviewed including acres, herd (or flock) size, and manure sold are provided in table 1. The average value is provided as well as a minimum and maximum value for each category, with the exception of the beef farm category where there were only three verified operations. Interviews of MAEAP producers who were verified as of January 1,2005, were conducted between December 2004 and February 2005. Large operations, CAFOs, constituted 17 of the 31 operations, while the remaining 14 operations were small or medium farms, AFOs. Swine farm operators were the most frequently interviewed (13 operations, $92 \%$ of verified swine producers at that point in time), followed by dairy (10 operations, $43 \%$ of then verified dairy producers), poultry (5 operations, $57 \%$ of then verified poultry producers), and beef (3 operations, $50 \%$ of then verified beef producers). While the operations examined are essentially a set of case studies and should not be considered representative of all 


\section{Table 2}

Average total Comprehensive Nutrient Management Plan (CNMP) writing costs.

\begin{tabular}{llllllll}
\hline & \multicolumn{2}{l}{ Cost per operation (2004 \$) } & & & & \\
\cline { 2 - 7 } Description & Beef & Dairy & Poultry & Swine & All farms & CAF0* & AF0† \\
\hline Producer CNMP cost & 1,992 & 4,082 & 2,160 & 1,605 & 2,531 & 3,382 \\
CNMP cost-share & 1,062 & 3,425 & 2,675 & 2,373 & 2,634 & 3,156 & 2,001 \\
\hline Total CNMP cost & 3,054 & 7,507 & 4,835 & 3,978 & 5,165 & 6,538 \\
\hline
\end{tabular}

* CAFO is a concentrated animal feeding operation defined as equal to or more than 1,000 animal units.

† AFO is an animal feeding operation defined as less than 1,000 animal units.

Michigan livestock operations, they did contain the majority of all operations that were MAEAP-verified at the time of our research. As such, we believe they are representative of the early MAEAP adopters and can help illustrate the financial and environmental consequences of environmental programs for livestock operations.

Compared to the average Michigan operation, the early adopters interviewed had larger operations in the case of beef (417 AU average compared to 89 for the Michigan average [USDA NASS 2006]), dairy (1,994 $\mathrm{AU}$ average compared to $150 \mathrm{AU}$ for the Michigan average), and swine (1,146 AU average compared to 1,130 for the Michigan average). The USDA National Agricultural Statistics Service does not release enough summary information to estimate average flock size for Michigan poultry operations.

Acres. Producers operated an average of 460.9 ha $(1,139 \mathrm{ac})$ with 286.1 ha $(707 \mathrm{ac})$ owned and 174.8 ha $(432 \mathrm{ac})$ rented. The average dairy operator farmed the most cropland (733.7 ha [1,813 ac]), including 431.8 ha $(1,067 \mathrm{ac})$ of owned cropland and 301.9 ha $(746 \mathrm{ac})$ of rented cropland. Acres operated were defined to include acreage used for crop production but to exclude facility and woodlot acres. Five of the 31 operations surveyed had no cropland acres. Excluding those operations with no cropland, the average operated acreage increased to 566.6 ha $(1,400 \mathrm{ac})$.

On some operations, all acreage was not available for spreading manure. Spreadable acres were defined to include land that livestock producers owned or rented, or land that was included in a verbal or written manure spreading agreement between the producer and the land's owner, excluding-because of Michigan Right to Farm Guidelines-those acres with $\mathrm{P}$ content greater than $150 \mathrm{ppm}\left(300 \mathrm{lb} \mathrm{ac}^{-1}\right)$, buffer strips, and grass waterways.

According to the Michigan Right to Farm guidelines for manure application, manure can be applied to land at nitrogen removal rates if the soil test for $\mathrm{P}$ is less than $167.0 \mathrm{~kg}$ $\mathrm{ha}^{-1}\left(149 \mathrm{lb} \mathrm{ac}^{-1}\right)$. If the soil test level is in the range of 168.1 to $335.1 \mathrm{~kg} \mathrm{ha}^{-1}$ (150 to $299 \mathrm{lb}$ $\left.\mathrm{P} \mathrm{ac}^{-1}\right)$, manure may be applied at $\mathrm{P}$ removal rates. If the $\mathrm{P}$ soil test is above $150 \mathrm{ppm}$ (300 $\mathrm{lb} \mathrm{ac}^{-1}$ ) or more, manure can not be applied to the soil (MDA 2006). Following MAEAP verification, spreadable acres averaged 524.1 ha $(1,295 \mathrm{ac})$, approximately $64.7 \mathrm{ha}(160 \mathrm{ac})$ more than the total operated acres and an increase of 36.4 ha $(90 \mathrm{ac}$ ) over pre-MAEAP levels (table 1). In response to the MAEAPidentified need for more spreadable acres, the dairy producers in our case studies increased their average number of spreadable acres by an average of 191.8 ha $(474 \mathrm{ac})$ through agreements with other landowners. Poultry operations in our case studies also increased spreadable acres by 163.1 ha (403 ac). The average swine operation in our case studies realized a reduction of 100.8 ha (249 ac) formerly used for spreading, because these acres had excessive levels of $\mathrm{P}$ (>150 ppm) and thus were not available for manure application under MAEAP verification.

Rented land was often obtained via lease agreements that were contracted for several years. Uncertainty is inherent in a one-year agreement, which may reduce a tenant's ability and willingness to adopt new pollution prevention practices. Thirty-nine percent of the 29 producers interviewed (12) had land rental contracts that explicitly addressed applying manure and/or nutrients to the land at agronomic rates.

Animal Units. The poultry producers in our case studies, on average, had the most AUs at 7,808 (table 1). The average poultry operation had nearly four times the number of AUs as the next largest species. Poultry producers also had the largest size range from 405 to 17,873 AUs. When manure was sold off-farm, it decreased the amount of manure spread on operated land. The poultry operators sold off-farm, on average, $83 \%$ of all manure generated on the verified opera- tion, an increase of $6 \%$ from pre-MAEAP levels (table 1). The CAFOs participating, on average, had 3,999 AUs (351 less than preMAEAP levels) and sold an average of $28 \%$ of the manure generated on the farm.

Financial Implications of Verification. The interviews delved into great detail to track changes in costs as a consequence of successfully participating in the voluntary program in Michigan. The average producer cost to write a CNMP for MAEAP verification across all farm types and sizes was $\$ 2,531$. The complete cost to write a CNMP was, in some cases, subsidized by EQIP cost share or reduced writing costs (or was even free when, for example, a plan writer was in need of plans to achieve their own certification). Comparing across livestock species, the average dairy producer participant's CNMP cost $(\$ 4,082)$ was over $\$ 2,500$ more expensive than any other species (table 2). This higher cost reflected the large number of enterprises and activities on those operations that the plan had to account for, such as milk house wastewater, silage leachate, and forage and grain enterprises. The average total cost of a CNMP, including cost share, was $\$ 5,165$. The average producer paid about half of the total cost $(51 \%)$. Beef producers in our case studies, on average, paid 65\% of CNMP costs, dairy producers paid $54 \%$, poultry producers paid $45 \%$, and swine producers paid $40 \%$. Participating CAFOs paid an average of $52 \%$ of the total cost, on average, while AFOs paid $43 \%$ on average. Producer CNMP writing costs were positively related to the number of AUs on the operation.

Operational changes due to MAEAP verification included such activities as manure spreading, supervision, record keeping, commercial fertilizer purchases, equipment use, fuel, utilities, insurance, manure testing, soil testing, and feed ration changes. Table 3 displays the average costs of operational changes that resulted from implementing the CNMP. Many producers had cost savings, which helped to offset the costs of implementing 
Table 3

Average total producer cost to become Michigan Agriculture Environmental Assurance Program (MAEAP) verified.

\begin{tabular}{|c|c|c|c|c|c|c|c|}
\hline \multirow[b]{2}{*}{ Description } & \multicolumn{7}{|c|}{ Total cost per operation (2004\$) } \\
\hline & Beef & Dairy & Poultry & Swine & All farms & CAFO* & AFO† \\
\hline CNMP cost & 1,992 & 4,082 & 2,160 & 1,605 & 2,531 & 3,382 & 1,498 \\
\hline Investment cost & 20,104 & 98,661 & 83,060 & 27,211 & 58,579 & 78,304 & 34,628 \\
\hline Total producer cost & $-9,044$ & 135,704 & 286,456 & 36,531 & 104,423 & 156,985 & 40,597 \\
\hline Standard deviation & 68,702 & 120,536 & 372,102 & 40,947 & 181,491 & 231,241 & 46,910 \\
\hline
\end{tabular}

* CAFO is a concentrated animal feeding operation defined as equal to or more than 1,000 animal units.

† AFO is an animal feeding operation defined as less than 1,000 animal units.

the CNMP. The greatest average savings was a decrease in annual nitrogen fertilizer costs. The largest savings to a single producer was $\$ 55,000$. The largest increase in commercial fertilizer cost was $\$ 45,000$, due to deficient nutrients in the cropland soils. No producer reported a decline in their crop yields due to the decreased amount of commercial fertilizer applied during the period analyzed. The fact that fertilizer application could be decreased-in some cases significantly-without adversely affecting crop yields indicated both the substantial amounts of $\mathrm{P}$ and potassium in the soil of many farms from past applications as well as inefficient use of fertilizer nutrients. This crop yield result is consistent with past studies, which have found that reduction in nitrogen fertilizer application can be accomplished without negative economic consequences (Johnson et al. 1991; Randhir and Lee 1997). One of the outcomes of the MAEAP for Michigan livestock producers was more awareness of the importance of efficient manure utilization consistent with other studies (e.g., Ribaudo et al. 2004). Less commercial P fertilizer, additional sales of manure, and lower insurance premiums also decreased the average producer costs.

The largest operational change expenses were increased fuel use, feed additives (which occurred only on poultry and swine farms), and additional energy. Changes in fuel costs ranged from $-\$ 15,580$ to $\$ 45,000$. Producers increased fuel use due to incorporating manure after application or hauling manure a longer distance based on manure and soil tests. The producers that realized a fuel cost savings did so because of spreading less commercial fertilizer, irrigating the liquid layer off the top of the manure lagoon, or switching to a spreader that knifed in the manure instead of a broadcast application, which eliminated tractor time required to incorporate manure into the soil.
In addition to the management changes, many producers were required to make capital investment changes in order to economically handle complementary operational changes in order to receive cost share. The types of investments made were probably influenced by the fact that during the time period encompassed by this research, CAFO operators were offered MAEAP verification in lieu of obtaining a National Pollutant Discharge Elimination System permit, provided that they did not have any discharge violations. The MAEAP verification requirements, therefore, were designed to match those associated with National Pollutant Discharge Elimination System permit requirements, and may have been more expensive than would otherwise have been the case if the criteria were those of the Michigan Right to Farm guidelines. The investment costs in table 3 were the annualized costs for capital investments from the MAEAP verification process. Each capital investment change implemented was depreciated over time. Twelve operations changed manure storage spending at an annual average cost of $\$ 1,563$. Manure storage was the largest expense for CAFOs. Large operations spent about twice the amount of money annually on capital investments as did small and medium operations. The CAFOs made more capital investment changes that were not eligible for EQIP cost-share, such as new machines or equipment. Ten producers, seven of which were CAFO operators, purchased machines or equipment to handle the extra distance and amount of manure being transported. Often the older equipment would take a long time to empty the lagoon or pit or require additional trips back and forth from the barnyard to the field. Attributing all these costs to MAEAP as was done in this study, biases the costs upwards, since machine purchases were not mandatory to become MAEAP verified.
Average total producer costs (not on an annual basis) for the verified farms were $\$ 104,423$ and ranged from a $\$ 9,044$ cost savings on the average beef farm to $\$ 286,456$ on the average poultry farm (table 3 ). It is important to note that the standard deviation was quite large in every category, reflecting the wide dispersion of producer expenditures related to MAEAP verification.

The total poultry producer cost for these case study farms was very large in absolute terms because a couple of the poultry operations were quite large (i.e., flock size) and added expenses included feed additives to decrease the $\mathrm{P}$ in the poultry litter as well as investment in machinery and equipment to handle the poultry litter. The CAFOs spent nearly four times as much as AFOs in terms of total operation expense for verification (table 3). Recall that CAFOs had about eight times as many AUs as AFOs. The CAFOs spent considerably more money to achieve verification in almost every category measured, including record keeping, crop consultants, manure spreading labor, fuel, and equipment use (to travel to farther away fields), feed additives, utilities, and capital investment (especially in manure storage). Ribaudo et al. 2003 concluded that the highest per-unit costs for meeting a nutrient-based manure management plan were often borne by the largest operations. This result was driven in part by the lack of additional land on which to spread manure.

Cost-Share Funds. Livestock producers who applied for MAEAP verification were eligible for cost-share assistance through the EQIP, administered by the USDA Natural Resources Conservation Service. Three farmers specifically mentioned the difficulties they incurred when applying for EQIP cost-share dollars. Some operators were hesitant to apply for EQIP money either because it took too much time to complete the lengthy application and/or the producer 
Table 4

Average annual producer cost per animal unit.

\begin{tabular}{|c|c|c|c|c|c|c|c|}
\hline \multirow[b]{2}{*}{ Description } & \multicolumn{7}{|c|}{ Annual cost per animal unit (2004 \$) } \\
\hline & Beef* & Dairy & Poultry & Swine & All farms & CAFOT & AFO $¥$ \\
\hline \multicolumn{8}{|c|}{ Annual producer cost } \\
\hline Average & 9.71 & 5.97 & 12.89 & 6.16 & 7.53 & 3.75 & 12.11 \\
\hline Standard deviation & 29.84 & 3.23 & 15.25 & 10.64 & 12.07 & 8.49 & 14.36 \\
\hline Minimum* & & 1.13 & -0.31 & -8.14 & -24.74 & -24.74 & -8.14 \\
\hline Maximum & & 11.32 & 38.13 & 34.45 & 38.13 & 13.20 & 38.13 \\
\hline \multicolumn{8}{|c|}{ Annual producer + cost share } \\
\hline Average & 31.64 & 6.35 & 13.23 & 7.71 & 10.48 & 4.06 & 18.27 \\
\hline Standard deviation & 52.04 & 3.38 & 14.97 & 13.92 & 18.61 & 8.57 & 24.29 \\
\hline Minimum & & 1.13 & -0.31 & -4.53 & -24.74 & -24.74 & -4.53 \\
\hline Maximum & & 11.44 & 38.13 & 49.40 & 77.82 & 13.20 & 77.82 \\
\hline
\end{tabular}

* Minimum and maximum values are not reported if there were less than four respondents in that category.

+ CAFO is a concentrated animal feeding operation defined as equal to or more than 1,000 animal units.

$\ddagger$ AFO is an animal feeding operation defined as less than 1,000 animal units.

did not want to inform governmental agency staff about changes they were making on the farm. While 23 producers received assistance to write the CNMP, only eight received EQIP cost-share for the capital investment changes. It should be noted that funds from EQIP could not be used for the cost of management changes or for machinery or equipment but could be used for lagoon manure storage. Nine producers were not eligible for any capital investment cost-share dollars because the changes they needed to make on their operation were not eligible for cost-share.

The average total cost-share funds given to the interviewed operators through EQIP, including the value of free CNMP preparation, was $\$ 16,177$. Eighty-five percent of the AFOs received some form of cost-share to assist with the cost of writing the CNMP or adding specific capital investment changes. Capital investments that were eligible for EQIP cost-share funds included manure storage, drainage, gutters, fences, buildings, roofs, grass waterways, buffers, and drives/ berms. On average, AFOs received \$113 $\mathrm{AU}^{-1}$ to assist with costs, while CAFOs received an average of $\$ 7 \mathrm{AU}^{-1}$. Swine producers received the lowest amount of cost-share, on average. Per AU, however, the swine producers received $\$ 26.70$ in costshare, nearly three times the amount dairy and poultry producers received per AU. Beef producers, on the other hand, received $\$ 406 \mathrm{AU}^{-1}$.

Per Animal Unit Costs. Examination of annual producer cost per AU facilitates comparison across size and species (table 4). Poultry producers had the largest average annual cost to become MAEAP verified at $\$ 12.89 \mathrm{AU}^{-1}$. Dairy operations paid the least per AU for verification at $\$ 5.97 \mathrm{AU}^{-1}$. Even with the substantial amount of cost-share received per AU, AFOs on average, paid nearly four times the amount CAFOs paid to become and maintain MAEAP verification $\$$ \$12.11 $\mathrm{AU}^{-1}$ compared to $\left.\$ 3.75 \mathrm{AU}^{-1}\right)$. The CAFOs were able to spread their fixed expenses over many more AUs and achieve a lower average total cost. Similarly, the investments made by CAFOs were for longer-term facilities (e.g., manure storage), which resulted in a lower annualized cost.

It is informative to compare these costs to other cost estimates for livestock compliance with environmental regulation. The USDA estimated average cost per cow per year to meet the 1990 Coastal Zone Management Act requirements ranged from $\$ 17.01$ to $\$ 34.63$ (Heimlich and Bernard 1995). For comparison to our results, recall that beef cows represent one $\mathrm{AU}$, while dairy cows represent 1.4 AUs. Thus, these USDA estimates for the Coastal Zone Management Act are generally larger than the costs of the MAEAP early adopters.

The US Environmental Protection Agency (USEPA) estimated the annualized compliance cost of CAFO regulations (USEPA 2002). The USEPA considered a number of farm types, sizes, and technology options. For comparison to our cost of compliance numbers, similar size operations by species for the Midwest region were chosen, along with the assumption that manure application would be limited by $\mathrm{P}$ requirements as is the case for Michigan farms. The USEPA estimated that for the Midwest region, for comparable size operations to the average, pre-tax cost of compliance was $\$ 6.45$ to $\$ 20.81 \mathrm{AU}^{-1}$ for beef operations, $\$ 0.62$ to $\$ 31.56 \mathrm{AU}^{-1}$ for dairy operations, $\$ 0.90$ to $\$ 3.00 \mathrm{AU}^{-1}$ for poultry, and $\$ 2.58$ to $\$ 4.45 \mathrm{AU}^{-1}$ for swine. The USEPA cost estimates did not include cost shares, instead assuming that producers bear all costs. Our program compliance cost values lend a degree of support to the USEPA's simulated estimates with our averages being squarely within their range for dairy and a bit higher for beef, poultry, and swine farms. The extensive use of cost shares might in part explain why our total costs are higher in some cases than USEPA estimates. It is possible that some producers spent more on program compliance in terms of capital expenditures and even plan writing because of government cost share.

Categorizing Operational Changes. Operators adjusted their management practices and purchased capital improvements to become verified with MAEAP. These management practices and purchases of capital investment can be categorized depending on their effects. "Field changes" were defined to include changes in machines to transport manure, equipment to spread manure, grass waterways, installing buffers, spreading labor, equipment use, soil testing, commercial fertilizer use, and fuel use. "Barnyard" changes included these categories: manure storage, fence, buildings, gutters, drainage, roof, and driveway/berms. "Animal manure" changes included manure testing, manure sold, and feed additives. Note that the effects of one change may have altered a decision made 
Table 5

Changes made and annual producer cost per animal unit.

\begin{tabular}{|c|c|c|c|c|c|c|c|c|}
\hline Description & & Beef & Dairy & Poultry & Swine & Total & CAFO* & AFO† \\
\hline \multicolumn{9}{|c|}{ Annual cost per animal unit (2004 \$) } \\
\hline Whole farm costs $\ddagger$ & & 7.76 & 2.34 & 1.69 & 2.73 & 2.92 & 1.92 & 4.14 \\
\hline Manure costs $\|$ & & 0.43 & 0.06 & 0.81 & 0.07 & 0.22 & 0.31 & 0.11 \\
\hline Barnyard costs\# & & 8.46 & 2.13 & 0.34 & 3.19 & 2.90 & 1.42 & 4.69 \\
\hline Total costs & & 9.71 & 6.10 & 12.89 & 6.17 & 7.57 & 3.83 & 12.12 \\
\hline Whole farm changes & 5 & 2.3 & 2.8 & 2.6 & 2.7 & 2.7 & 2.8 & 2.6 \\
\hline Field changes & 9 & 2.7 & 2.7 & 3.4 & 3.2 & 3.0 & 3.2 & 2.7 \\
\hline Manure changes & 3 & 0.7 & 0.8 & 0.8 & 0.5 & 0.7 & 0.9 & 0.4 \\
\hline
\end{tabular}

* CAFO is a concentrated animal feeding operation defined as equal to or more than 1,000 animal units.

† AFO is an animal feeding operation defined as less than 1,000 animal units.

$\ddagger$ Whole farm changes included: record keeping labor, crop consultant/technical service provider, energy and utility, supervision hours, and insurance premium.

$\S$ Field changes included: machines to transport manure, equipment to spread manure, grass waterways, buffers, spreading labor, equipment usage, soil testing, commercial fertilizer, and fuel.

|| Manure changes included: manure testing, manure sold, and feed additives.

\# Barnyard changes included manure storage, fence, buildings, gutters, drainage, roof, and driveway/berms.

in a different category. For example, selling less animal manure may have increased the need for additional manure storage (a barnyard change) and also increased the distance manure was hauled to a field that had a soil test $\mathrm{P}$ below $150 \mathrm{ppm}\left(300 \mathrm{lb} \mathrm{ac}^{-1}\right)(\mathrm{a}$ field change). Five changes made on each specific operation affected many aspects of the entire operation, and thus were categorized as whole farm changes. "Whole farm" changes included those associated with record-keeping labor, the services of crop consultant/technical service providers, energy and utility use, supervision hours, and insurance premiums. Not every change made on an operation to comply with MAEAP will necessarily result in an associated environmental quality improvement.

In aggregate, whole farm and barnyard changes were the most expensive alterations that occurred-averaging \$2.92 and \$2.90 $\mathrm{AU}^{-1}$, respectively (table 5). Livestock manure changes cost the least per AU, on average, at $\$ 0.22 \mathrm{AU}^{-1}$. Beef operators, on average, paid for nearly all the whole farm changes with the money they saved from the field changes they implemented-namely using less fertilizer. The average beef producer made more changes, while poultry operators spent more money per AU than any other species category (table 5).
Comparing CAFOs to AFOs reveals that AFOs spent considerably more per AU for whole farm, field, and barnyard costs, while CAFOs spent more for manure costs. The AFOs tend to have older technology and facilities, while CAFOs, many of which have expanded in recent years, take advantage of newer production technology sets. The result was that AFOs were required to spend considerably more on an annualized per AU basis to comply with requirements relative to runoff and drainage issues.

In a New York dairy study, nine variables were examined to evaluate the risk of $\mathrm{P}$ runoff: four types of pastures, the barnyard, cow paths, forest, and corn, and hay fields (Hively 2005). Barnyards and cow paths had the quickest $\mathrm{P}$ overland flow, and they had the highest concentration of dissolved and particulate $\mathrm{P}$ in that runoff. This New York research suggested that the barnyard was critical for P loading (Hively 2005). Further, it suggests that many of the 31 Michigan operations surveyed in this research lowered their risk of having a manure discharge into surface water by updating their manure storage, roofing and curbing the manure holding pads, or diverting water from a lot to a lagoon. At least two of the thirty-one operations surveyed altered their manure storage to eliminate a direct manure runoff into sur- face water. If properly built and maintained, changes made to the barnyard assisted in reducing the potential to transport $\mathrm{P}$ to surface waters because these changes diverted runoff or prevented runoff at the source.

The barnyard changes made on the 31 operations accounted for, on average, approximately $38 \%$ of the producer's change in annual costs $\left(\$ 2.90 \mathrm{AU}^{-1}\right)$ (table 5). If an operator made barnyard changes, the operator was more likely to receive a larger amount of cost-share per AU (correlation 0.49). A strong correlation was expected, as all of the barnyard changes were eligible for EQIP costshare funds. The operators that made barnyard changes were also likely to have fewer AUs (correlation -0.25). There was, however, no correlation between the cost of becoming MAEAP verified and the number of barnyard management changes implemented.

Environmental Outcomes. While there may be many environmental benefits from the facilities and management practice changes that the farmers made to comply with MAEAP, only two measures were used to examine environmental outcomes: the change in farm operation $\mathrm{P}$ mass balance and the change in field P-Index scores. Both methods were used to quantify farm environmental outcomes that occurred through MAEAP verification. The assumption was that 
Table 6

Change in phosphorus cropland balance on 25 operations due to the Michigan Agriculture Environmental Assurance Program verification.

\begin{tabular}{|c|c|c|c|c|c|c|c|}
\hline \multirow[b]{2}{*}{ Description } & \multicolumn{7}{|c|}{ Pounds of $\mathrm{P}_{2} \mathrm{O}_{5}$ per year } \\
\hline & Beef* & Dairy & Poultry & Swine & Total & CAFO† & AFO \\
\hline \multicolumn{8}{|c|}{$\mathrm{P}_{2} \mathrm{O}_{5}$ mass balance before verification } \\
\hline Standard deviation & 15,797 & 57,837 & 127,178 & 19,179 & 55,515 & 76,077 & 20,234 \\
\hline Minimum & & $-58,335$ & $-196,733$ & $-29,467$ & $-196,733$ & $-196,733$ & $-38,086$ \\
\hline Maximum & & 97,689 & 95,271 & 44,641 & 97,689 & 97,689 & 40,780 \\
\hline Average & $-12,675$ & $-20,411$ & $-41,341$ & $-10,391$ & $-18,332$ & $-29,111$ & $-6,654$ \\
\hline Standard deviation & 17,046 & 26,571 & 104,645 & 11,111 & 41,686 & 53,799 & 18,650 \\
\hline Minimum & & $-63,751$ & $-196,733$ & $-29,467$ & $-196,733$ & $-196,733$ & $-38,086$ \\
\hline Maximum & & 13,448 & 31,369 & 8,206 & 31,369 & 180 & 31,369 \\
\hline \multicolumn{8}{|c|}{ Change in $\mathrm{P}_{2} \mathrm{O}_{5}$ balance } \\
\hline
\end{tabular}

Note: $\mathrm{P}_{2} \mathrm{O}_{5}=$ phosphorus pentoxide.

* Minimum and maximum values are not reported because there were only three farms in this category.

† CAFO is a concentrated animal feeding operation defined as equal to or more than 1,000 animal units.

$\ddagger$ AFO is an animal feeding operation defined as less than 1,000 animal units.

if there was an improvement in either of these measures, then there should be a reduction in the amount of $\mathrm{P}$ entering Michigan waters.

The $\mathrm{P}$ balance is a measure of how much the net import of $\mathrm{P}$ must change for the farm to avoid overapplication of nutrients. As $\mathrm{P}$ can lead to harmful plant growth in freshwater systems, such as the ones that Michigan possesses, it must be applied at appropriate agronomic rates. Phosphorus mass balance scores were calculated by subtracting the "exported"P (e.g., crop sales, animal sales, and manure moved off-farm) from the amount "imported" onto the farm (e.g., commercial fertilizer and feed purchases). The variables used to calculate the cropland P mass balance included (1) the amount of $\mathrm{P}$ in manure, (2) the total quantity of manure, (3) the number of spreadable acres (i.e., acres below 150 ppm [300 lb P ac$\left.\left.{ }^{-1}\right]\right)$, (4) the amount of $\mathrm{P}$ the crops on those spreadable acres would use during a growing season, and (5) the amount of manure moved off-farm. The application of commercial fertilizer was assumed to be determined after the livestock producer knew the cropland $\mathrm{P}$ mass balance. Therefore, if a farm was out of cropland mass balance according to the farm CNMP calculations, it was assumed that no commercial fertilizer would be spread. Due to the variation among the CNMPs collected, some details could not be added to the $\mathrm{P}$ mass balance score (e.g., $P$ in feed) that would have added to the precision of the score. Variables that directly altered the cropland's P mass balance included acquiring additional spreadable acres, moving manure off-farm, fertilizer purchases, and feed purchases.

If the calculations revealed that an operation had a $\mathrm{P}$ mass balance score that was within plus or minus $20 \%$ of the initial pounds of $\mathrm{P}$ consumed by crops, then that farm was considered in balance. This range accounted for the potential errors in calculating $\mathrm{P}$ in manure, soil $\mathrm{P}$, and/or crop uptake. If a farm was out of balance, then it had a positive score, signifying that the crops could not consume all of the $\mathrm{P}$ that was applied via manure application and/or not enough manure had been sold off-farm.

The average dairy farm examined generated more $\mathrm{P}$ than the crops could use-and therefore, was out of mass balance-prior to implementation of the CNMP and MAEAP verification (table 6). Other livestock species operations (e.g., hogs, poultry) had at least one farm that was out of mass balance prior to becoming MAEAP verified. Even farms in balance could benefit from the changes associated with MAEAP verification by improving their public relations and potentially reducing their liability exposure. After becoming MAEAP verified, all species had an average $\mathrm{P}$ mass balance score that was below zero or in mass balance. Ninety-two percent of the 23 farms (e.g., those farms for which a $\mathrm{P}$ mass balance score was calculated) were in mass balance after becoming MAEAP veri- fied. It is expected that farms that are in mass balance have reduced their farm's potential for soil $\mathrm{P}$ buildup and eventual runoff into surface water.

After becoming MAEAP verified, CAFOs, which on average were in deficit-that is, already in mass balance-to begin with, decreased their $\mathrm{P}$ mass balance by an average of $10,772.8 \mathrm{~kg}(23,750 \mathrm{lb})$ (table 6). The AFOs had a much smaller change in mass balance but still had a decrease of $\mathrm{P}$ after verification. Two CAFO operators sold some of their animals, an action that aided these farms coming into or below the P mass balance. The average dairy operation went from a $1,630.7 \mathrm{~kg}(3,595 \mathrm{lb})$ surplus of $\mathrm{P}$ to a 9,258.3 kg (20,411 lb) deficit.

Twelve farms were categorized as environmentally high risk prior to becoming MAEAP verified. Their fields had an average score of 18.5 on the P-Index, slightly above the 18 threshold, with the farm averages ranging from 27.7 to 8.7. After these farms became verified, the P-Index score on these same fields ranged from 20.5 to 7.7 . This result reflects the adoption of environmentally beneficial practices to decrease P runoff. After the dairy operations became MAEAP verified, an average P-Index score of 14.9 was achieved, which signified a lowered potential for $\mathrm{P}$ runoff on the high-risk fields.

To lower the P-Index score of a field, the livestock producer could have made several different management changes or planted 


\section{Table 7}

Producers motivation to become Michigan Agriculture Environmental Assurance Program verified.*

\begin{tabular}{|c|c|c|c|c|c|c|c|}
\hline \multirow[b]{2}{*}{ Motivating factor } & \multicolumn{7}{|c|}{ Percent of operations responding } \\
\hline & Beef & Dairy & Poultry & Swine & Total & CAFO† & AFO \\
\hline Environmental regulations & 33 & 60 & 100 & 46 & 58 & 71 & 43 \\
\hline Obtain assistance & 33 & 20 & 20 & 31 & 26 & 29 & 21 \\
\hline Decrease lawsuit and fine risk & 0 & 20 & 20 & 23 & 19 & 24 & 14 \\
\hline Increase community awareness & 0 & 30 & 0 & 8 & 13 & 18 & 7 \\
\hline Number of respondents & 3 & 10 & 5 & 13 & 31 & 17 & 14 \\
\hline
\end{tabular}

* Producers could choose more than one motivation that prompted their beginning the Michigan Agriculture Environmental Assurance Program verification process and thus totals do not sum to $100 \%$.

+ CAFO is a concentrated animal feeding operation defined as equal to or more than 1,000 animal units.

$\ddagger$ AFO is an animal feeding operation defined as less than 1,000 animal units.

a buffer strip or grass waterway. A change in the P-Index score usually resulted from decreasing P runoff potential through less soil erosion (by adopting practices such as planting buffers or grass waterways and observing setbacks), applying manure over a growing crop, incorporating manure, or applying less manure or commercial P. More livestock producers chose to implement buffer strips, change crop rotation, or alter tillage practices rather than change the method or amount of $\mathrm{P}$ that was applied to a field. The most common change made on a field was adding buffers or setbacks, which also increased the distance to surface water.

Motivations. The motivation to undertake a CNMP came from many sources (table 7). Fifty-eight percent of interviewed producers (18) became verified due, in part, to perceived current or future environmental regulations affecting their farm. This perception was most influential with large farm producers; $71 \%$ of CAFOs (12) and $43 \%$ of AFOs (6) listed environmental regulations as a reason they became verified. Sixty percent of the ten interviewed dairy producers noted environmental regulations as a motivating factor. The interviewed producers were not motivated either by drinking water quality on their farm or by landlord requirements. These results are consistent with other research on Michigan dairy producers' motivations for participating in the MAEAP (Abdulkadri et al. 2009).

Participation in voluntary programs may have been motivated by the producers' stewardship ethics. Eight producers mentioned that they became verified because they felt it was the "right thing to do." For some producers, this statement meant they were doing the right things for the environment and their neighbors or they were setting a good example for other livestock producers in the state. Still others mentioned they foresaw better profits resulting from participation. The potential for decreased operational costs and other benefits indicates that disseminating these results might encourage future participation in voluntary programs.

Another strong motivation mentioned was the desire to obtain technical and financial assistance. As part of the MAEAP verification process, producers received assistance to complete the CNMP, to understand the regulations affecting livestock production, and to access sources of financial assistance. These results support the use of cost share programs, such as EQIP, to entice producer participation in environmental programs (Ribaudo et al. 2004).

\section{Summary and Conclusions}

This study examined the costs of farms that self-selected into early adoption of a voluntary environmental assurance program in Michigan. Some of the operations actually increased net revenues through careful scrutiny of their management that lowered fertilizer purchases. On average, the operations spent $\$ 5$ to $\$ 10 \mathrm{AU}^{-1}$ annually to comply with the environmental assurance program. Many of the interviewed farmers spoke of benefits from participation. Because not all of the changes reported by producers were required by the program, such as some equipment purchases or storage lagoons larger than necessary to meet Michigan's Right to Farm Guidelines, the reported total costs to become verified were biased upwards from the minimum necessary verification costs. However, these costs were often offset by cost share funds that were available and, in some cases, had free or reduced CNMP writing costs. Interestingly, in another study of 21 MAEAP dairy producers, $63.2 \%$ felt that the benefits from participating in the MAEAP exceeded the costs of participating (Abdulkadri et al. 2009). The conclusion that the benefits from participating are perceived as positive is consistent with a study by Poe et al. Poe and colleagues examined ex ante environmental regulation on New York dairy farms and found that willingness to participate in voluntary programs was strongly related with larger herd size. Operators of the larger herds indicated a willingness to pay of about $\$ 1,200$ per farm.

The environmental impact of the MAEAP on the $\mathrm{P}$ mass balance and $\mathrm{P}$ Index of MAEAP-verified farms revealed that verified farms reduced their $\mathrm{P}$ pollution potential. Ninety-two percent of 25 farms surveyed were in mass balance after they became MAEAP verified. With farms in mass balance, the potential $\mathrm{P}$ build up in the soil on these farms was diminished. The 12 highest risk farms had a P-Index score above the threshold (18) before they became MAEAP verified. As a result of implementing additional agronomic field management practices and reducing the amount of field erosion, these high-risk livestock farms reduced their field P-Index score average to below 15. The P-Index score of these farms, after becoming MAEAP verified, was below the threshold, which indicated that a low risk of $\mathrm{P}$ runoff potential from a field had been achieved. Many of the changes implemented on an operation were due to an increased knowledge and understanding of agronomic conditions, of water flow, of animal management, and of environmental 
regulations as well as by the maintenance of more accurate records.

While the number of MAEAP verified farms is small relative to the potential total, it is possible that the program is having a positive influence even on operators that are not verified. Thus, it is difficult to conclude exactly how much of an impact MAEAP has had on improving environmental outcomes. To improve verified farm numbers, the results of this study suggest that MAEAP administrators can encourage those producers who are verified to explain the advantages to those livestock producers who have not yet participated.The MAEAP administrators can also highlight the implications of current and foreseeable regulations for specific livestock farms nutrient management practices since these regulations were prime motivators. The enhanced availability of financial and technical assistance via the MAEAP verification route is a strong motivator for many livestock producers and should also be emphasized in recruiting participants.

\section{References}

Abdulkadri, A., S. Miller, S. Batie, and S. Joshi. 2009. Environmental Stewardship of Dairy Producers in MAEAP. Michigan Dairy Review 14(1):13-16.

Alberini, A., and K. Segerson. 2002. Assessing voluntary programs to improve environmental quality., Special Issue. The Practice of Environmental and Resource Economics. Environmental and Resource Economics 22(2):157-184.

Dartt, B., and G. Schwab. 2001. Crops and Livestock Budgets Estimates for Michigan. Agricultural Economics Report No. 609. September 2001.

Heimlich, R., and C.H. Bernard. 1995. Economics of Agricultural Management Practices in the Coastal Zone. USDA Economic Research Service Agricultural Economics Report 698.

Hively, W.D., R.B. Bryant, and T.J. Fahey. 2005. Phosphorus concentrations in overland flow from diverse locations on a New York Dairy Farm. Journal of Environmental Quality 34:1224-1233.

Johnson, S.L., R.M. Adams, and G.M. Perry. 1991. The onfarm costs of reducing groundwater pollution. American Journal of Agricultural Economics 73:1063-1073.

MAEAP (Michigan Agriculture Environmental Assurance Program). 2011. http://www.maeap.org.

Massey, R. 1998. Manure Distribution Cost Analyzer. http:// agebb.missouri.edu/mgt/analyzer.htm.

MDA (Michigan Department of Agriculture). 2008. Generally Accepted Agricultural and Management Practices for Manure Management and Utilization.
Ouyang, D., and C. Laboski. 2005. Report for 2005 MI50B: Use of Spatial Data and GIS in Evaluating Manure Application Risk Index.

Poe, G.L., N.L. Bills, C. Bellows, P. Crosscombe, R.K. Koelsch, M.J. Kreher, and P. Wright. 2001. Will voluntary and educational programs meet environmental objectives? Evidence from a survey of New York Dairy Farms. Review of Agricultural Economics 23:473-491.

Randhir, T.O., and J.G. Lee. 1997. Economic and water quality impacts of reducing nitrogen and pesticide use in agriculture. Agricultural and Resource Economics Review 26:39-51

Ribaudo, M., A. Cattaneo, and J. Agapoff. 2004. Cost of meeting manure nutrient application standards in hog production: The roles of EQIP and fertilizer offsets. Review of Agricultural Economics 26(4):430-444.

Ribaudo, M., N. Gollehon, M.Aillery,J. Kaplan, R.Johansson, J. Agapoff, L. Christensen, V. Breneman, and M. Peters. 2003. Manure Management for Water Quality: Cost to Animal Feeding Operations of Applying Manure Nutrients to Land. US Department of Agriculture Economic Research Service. Agricultural Economic Report No. (AER-824), June.

Sharpley, A.N., T. Daniel, T. Sims, J. Lemunyon, R. Stevens, and R. Parry. 2003. Agriculture Phosphorus and Eutrophication Second Edition. ARS-149. Washington DC: USDA Agricultural Research Service.

US Department of Labor Bureau of Labor Statistics. 2005. Farm Machinery and Equipment Manufacturing and Farm Products. Washington, DC.

USDA NASS (National Agricultural Statistics Service). 2004. Agricultural Statistics. Washington, DC: USDA National Agricultural Statistics Service.

USDA NASS. 2006. Michigan Agricultural Statistics 200506. Michigan Field Office, East Lansing, MI.

USDA NRCS (Natural Resources Conservation Service). 2003. Executive Summary: Costs Associated with Development and Implementation of Comprehensive Nutrient Management Plans. Washington, DC: USDA Natural Resources Conservation Service.

USEPA (US Environmental Protection Agency). 2002. Economic Analysis of the Final Revisions to the NPDES and Effluent Guidelines for CAFOs: Appendix B. http://cfpub.epa.gov/npdes/afo/cafodocs.cfm. 